Article

\title{
Uncertainty and Sensitivity Analysis of a Remote-Sensing-Based Penman-Monteith Model to Meteorological and Land Surface Input Variables
}

\author{
Nobuhle P. Majozi ${ }^{1,2, *}$, Chris M. Mannaerts ${ }^{2} \mathbb{D}$, Abel Ramoelo ${ }^{3,4} \mathbb{D}$, Renaud Mathieu ${ }^{4,5}$ and Wouter Verhoef $^{2} \mathbb{D}$ \\ 1 Precision Agriculture Group, Advanced Agriculture and Food, Council for Scientific and Industrial Research, \\ Pretoria 0001, South Africa \\ 2 Department of Water Resources, Faculty of Geo-Information Science and Earth Observation, University of \\ Twente, 7500 AE Enschede, The Netherlands; c.m.m.mannaerts@utwente.nl (C.M.M.); \\ w.verhoef@utwente.nl (W.V.) \\ 3 Scientific Services, South African National Parks, Pretoria 0001, South Africa; abel.ramoelo@sanparks.org \\ 4 Department of Geography, Geoinformatics and Meteorology, University of Pretoria, \\ Pretoria 0001, South Africa; r.mathieu@irri.org \\ 5 International Rice Research Institute, Geospatial Science and Modelling Cluster, Sustainable Impact Platform, \\ Pili Drive, Los Baños, Laguna 4031, Philippines \\ * Correspondence: nmajozi@csir.co.za; Tel.: +27-12-841-3840
}

\section{check for} updates

Citation: Majozi, N.P.; Mannaerts, C.M.; Ramoelo, A.; Mathieu, R.; Verhoef, W. Uncertainty and Sensitivity Analysis of a

Remote-Sensing-Based

Penman-Monteith Model to Meteorological and Land Surface Input Variables. Remote Sens. 2021, 13, 882. https://doi.org/10.3390/ rs13050882

Academic Editor: Yang Hong

Received: 11 January 2021

Accepted: 15 February 2021

Published: 26 February 2021

Publisher's Note: MDPI stays neutral with regard to jurisdictional claims in published maps and institutional affiliations.

Copyright: (c) 2021 by the authors. Licensee MDPI, Basel, Switzerland. This article is an open access article distributed under the terms and conditions of the Creative Commons Attribution (CC BY) license (https:/ / creativecommons.org/licenses/by/ $4.0 /)$.

\begin{abstract}
This study analysed the uncertainty and sensitivity of core and intermediate input variables of a remote-sensing-data-based Penman-Monteith (PM-Mu) evapotranspiration (ET) model. We derived absolute and relative uncertainties of core measured meteorological and remote-sensing-based atmospheric and land surface input variables and parameters of the PM-Mu model. Uncertainties of important intermediate data components (i.e., net radiation and aerodynamic and surface resistances) were also assessed. To estimate the instrument measurement uncertainties of the in situ meteorological input variables, we used the reported accuracies of the manufacturers. Observational accuracies of the remote sensing input variables (land surface temperature $(L S T)$, land surface emissivity $\left(\varepsilon_{s}\right)$, leaf area index $(L A I)$, land surface albedo $(\alpha)$ ) were derived from peer-reviewed satellite sensor validation reports to compute their uncertainties. The input uncertainties were propagated to the final model's evapotranspiration estimation uncertainty. Our analysis indicated relatively high uncertainties associated with relative humidity $(R H)$, and hence all the intermediate variables associated with $R H$, like vapour pressure deficit $(V P D)$ and the surface and aerodynamic resistances. This is in contrast to other studies, which reported LAI uncertainty as the most influential. The semi-arid conditions and seasonality of the regional South African climate and high temporal frequency of the variations in $V P D$, air and land surface temperatures could explain the uncertainties observed in this study. The results also showed the ET algorithm to be most sensitive to the air-land surface temperature difference. An accurate assessment of those in situ and remotely sensed variables is required to achieve reliable evapotranspiration model estimates in these generally dry regions and climates. A significant advantage of the remote-sensing-based ET method remains its full area coverage in contrast to classic-point (station)-based ET estimates.
\end{abstract}

Keywords: sensitivity analysis; uncertainty analysis; remote sensing; Penman-Monteith; evapotranspiration; absolute uncertainty; relative uncertainty

\section{Introduction}

Evapotranspiration is dependent on meteorological variables such as air temperature (Tair), solar radiation $(R s)$, humidity $(R H)$ and wind speed $(u)$ and biophysical characteristics of the land surface and vegetation. It is considered the most uncertain component of the hydrological cycle due to its variation both in space and time, and the complex hydrometeorological processes involved. Hence, it is a challenging process to measure 
and model. The advent of remote sensing technology has made it possible to develop models of varying complexity to capture this variation [1-6]. However, like any model, these models propagate varying errors through the final output. Errors are linked either to: (i) an incomplete understanding and simplified descriptions of modelled processes compared to reality, or (ii) input variables and parameterisations used in the model [6-9].

While uncertainty analysis (UA) is performed to evaluate the degree of confidence of the model output and system performance indices by identifying and quantifying possible model input errors, sensitivity analysis (SA) quantifies how the uncertainty of different model inputs impacts the overall model output [10]. They rank the importance of input variable errors in the final result and highlight the need to assess the physical meaning of model parameters and their relative influence on the output. Sometimes used interchangeably, UA and SA are critical steps in model development and calibration, especially in hydrological, ecological and crop modelling, as they answer questions like where data collection efforts should focus, what degree of care should be taken for parameter estimation and the relative importance of various parameters [11]. As described in the Guide to the Expression of Uncertainty in Measurement [12], UA is divided into Type A $\left(\mathrm{U}_{\mathrm{A}}\right)$, which evaluates measurement uncertainty using a statistical analysis of a series of measurements, and Type $B\left(U_{B}\right)$, which quantifies any uncertainty other than the statistical analysis, including the instrument manufacturer's published accuracy and the quoted accuracies for remote sensing products. Sensitivity analysis (SA) techniques currently being used range from the simplest local (LSA) to global SA (GSA) techniques [13,14], from differential to Monte Carlo analysis $[15,16]$, from measures of importance to sensitivity coefficients and from regression methods to variance-based techniques [17-21].

Assessing the uncertainty and sensitivity of the different evapotranspiration models is important to identify which input variables most impact the models and recommend the improvement of the accuracy of these input variables. In other instances, the analyses identify the input variables that least impact the models to eliminate them and simplify the models. Furthermore, these analyses are critical to understanding the possible implications of climate change on the catchment water balance. Most studies have focused on the sensitivity of ET model outputs to different inputs, with varying outcomes. For instance, Talsma, et al. [22] employed the Monte Carlo sensitivity analysis to explore how the input variable uncertainty affect the output of three global ET models, i.e., the Penman-Monteith model from the Moderate Resolution Imaging Spectroradiometer (PM-MOD), the Global Land Evaporation Amsterdam Model (GLEAM) and the Priestley-Taylor Jet Propulsion Laboratory model (PT-JPL). Numerous sites were investigated, with results showing that all models were most sensitive to NDVI, RH and net radiation (Rnet) for the three models, respectively, at 10\% input uncertainty. Pérez, et al. [23] showed that the Priestly-Taylor (PT) model was sensitive to the PT parameter $(\alpha)$ in their study. In a study to analyse the sensitivity of the FAO-56 Penman-Monteith method, Sharifi and Dinpashoh [24] found this model to be most sensitive to mean temperature at most sites. In Australia, Guo, et al. [25] investigated the sensitivity of the PM and PT models to climate variables, air temperature (Tair), relative humidity $(R H)$, wind speed $(\mathrm{u})$ and solar radiation $(\mathrm{Rs})$. In drier and warmer regions, they found the two models to be most sensitive to $\mathrm{u}$ and least sensitive to $R H$. Most of these studies only varied the input variables by fixed percentage bounds without taking into account the input variable limits and rarely use measurement instrument accuracy limits as a basis for comparison. Moreover, only a few focused on how input variable uncertainty is propagated to the final ET uncertainty [26]. Hofreiter and Jirka [27] used the International Organisation for Standardisation Guides to the expression of Uncertainty in Measurement (ISO GUM) method to evaluate the uncertainty of the PM associated with net radiation measurements. Using the same method, Chen, et al. [28] analysed the uncertainty of the Stanghhellini and Baille ET equations to errors associated with instruments used to measure input variables. An uncertainty analysis study of the PM model to both climate variables and land surface parameters is necessary to determine the degree of confidence of the model in relation to input error and/uncertainty. This will also give an indication 
of how the model reacts to any change in climatic variables, such as air temperature, net radiation and water availability. Furthermore, through this section, an analysis of how land use/land cover change impacts on ET variation is provided.

The emergence of RS-based ET modelling presents another opportunity to assess not only the reaction of the ET models to climatic input variables but also to land surface parameters, which culminates in how land-use change impacts on ET. Few studies have investigated the sensitivity of ET models to remote sensing input parameters [29,30]. This indicates that more work needs to be done to understand the sensitivity of ET models to remote sensing land surface parameters, especially considering the number of remote sensing-based ET models that have been extensively evaluated across different bioclimates.

A previous study by Majozi, et al. [31] reported a distinct reasonable performance of the PM model as modified by $\mathrm{Mu}$, et al. [32], Mu, et al. [33] (PM-Mu) during high ET periods. Consequently, this study investigated the sensitivity of this model to its input variables, i.e., both meteorological and land surface characteristics, in situ and remote sensing. This study also quantified the uncertainty of the input variables and how these were propagated into the final ET uncertainty. Generally, the PM model is a structurally complex and data-intensive model presenting a combination of the energy balance and aerodynamic components. This makes it important to endeavour to understand and quantify potential errors and uncertainties of the input data and how these impact the final ET output. This process will, therefore, identify the inputs that are most influential and correlated with the dependent variable in a semi-arid environment, in order to improve parameterisations that could eventually improve our results. This study will also highlight the possible implications of land use/land cover and climate change on the hydrology of the study areas.

\section{Materials and Methods}

\subsection{Site Description}

ET was estimated using data from two eddy covariance flux tower sites located in savanna and grassland southern African ecoregions (Figure 1). The year 2012 daily data were selected for both sites and considered in this study:

i. The Skukuza FLUXNET site, located in a savanna ecosystem in the Kruger National Park, South Africa, sits at $365 \mathrm{~m}$ above mean sea level. The site is characterised by low rainfall averaging $550 \pm 160 \mathrm{~mm}$ per annum between November and April, with notable inter-annual variability, and temperatures ranging between 15.6 and $29.6{ }^{\circ} \mathrm{C}$, with a mean of $22.6^{\circ} \mathrm{C}$. Soils in this part of the park are generally shallow, comprising coarse sandy to sandy-loam texture. The vegetation is mainly open woodland, with approximately $30 \%$ tree canopy cover of mixed Acacia and Combretum savanna types. The canopy height is $5-8 \mathrm{~m}$, with occasional trees (mostly Sclerocarya birrea) reaching $10 \mathrm{~m}$. The grassy and herbaceous understorey comprises grasses such as Panicum maximum, Digitaria eriantha, Eragrostis rigidor and Pogonarthria squarrosa. The eddy covariance system, which has been running since 2000, was installed on a vegetation transition characterised by a catenal pattern of soils and vegetation, with broad-leaved Combretum savanna on the crests dominated by Combretum apiculatum, and fine-leaved Acacia savanna in the valleys dominated by Acacia nigrescens [34,35].

ii. Welgegund flux tower site $\left(26^{\circ} 34^{\prime} 10^{\prime \prime} \mathrm{S}, 26^{\circ} 56^{\prime} 21^{\prime \prime} \mathrm{E}\right)$ is located on a semi-arid, subtropical grazed grassland plain. It is situated approximately $100 \mathrm{~km}$ west of Johannesburg, in South Africa. The mean annual rainfall is $540 \pm 112 \mathrm{~mm}$, spreading between October and April. Temperature ranges between 0 and $30{ }^{\circ} \mathrm{C}$, with an average of $18{ }^{\circ} \mathrm{C}$. The dominant vegetation comprises grasses, geophytes and herbs. The dominant grass species are Hyparrhenia hirta and Sporobolus pyramidalis. Non-grassy forbs include Acacia sieberiana, Rhus rehmanniana, Walafrida densiflora, Spermacoce natalensis, Kohautia cynanchica and Phyllanthus glaucophyllus Räsänen, et al. [36]. 


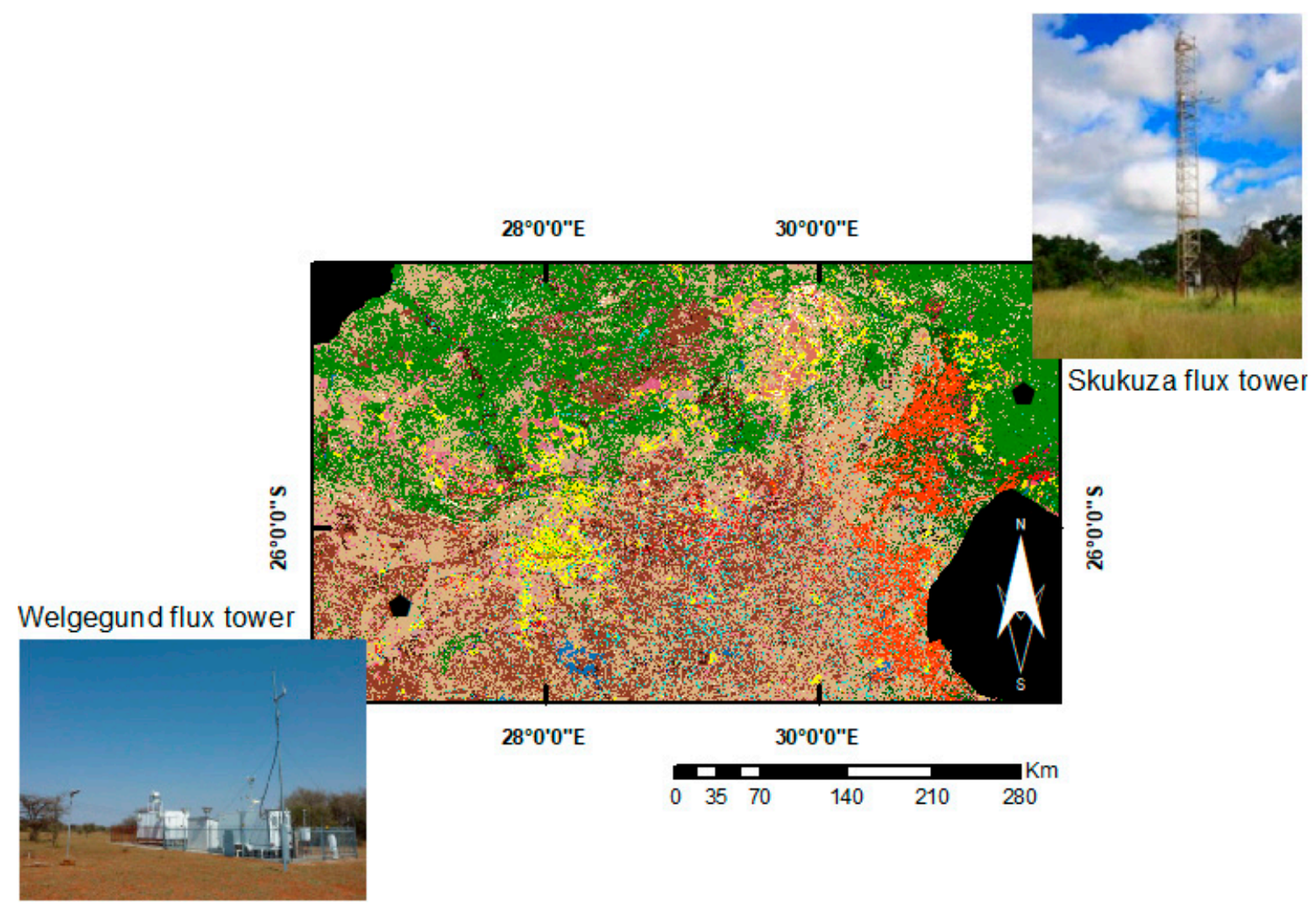

Figure 1. Skukuza and Welgegund flux tower sites. Welgegund image sourced from https://www.welgegund.org/.

\subsection{Remote-Sensing-Based Penman-Monteith Model}

The Penman-Monteith model as modified by Mu et al. [32,33] was assessed in this study. The latent heat flux was estimated as:

$$
\lambda E=\frac{s * A+\rho * C p *\left(e_{s a t}-e\right) / r_{a}}{s+\gamma *\left(1+\frac{r_{s}}{r_{a}}\right)}
$$

where $\lambda E$ is the latent heat flux $\left(\mathrm{Wm}^{-2}\right)$ and $\lambda$ is the heat of vaporisation $\left(\mathrm{Jkg}^{-1}\right), s$ is the slope of the curve relating saturated vapour pressure to temperature $\left(\mathrm{PaK}^{-1}\right), A$ is available energy $\left(\mathrm{Wm}^{-2}\right)$, is the air density $\left(\mathrm{kgm}^{-3}\right), \mathrm{C} p$ is the specific heat capacity of air $\left(\mathrm{Jkg}^{-1} \mathrm{~K}^{-1}\right)$, $\gamma$ is the psychrometric constant $\left(\mathrm{PaK}^{-1}\right), e_{s a t}$ is the saturation vapour pressure $(\mathrm{kPa}), e$ is the actual vapour pressure $(\mathrm{kPa})$, where $e_{s a t}-e=$ vapour pressure deficit $(V P D, \mathrm{kPa}), r_{a}\left(\mathrm{sm}^{-1}\right)$ is the aerodynamic resistance and $r_{S}\left(\mathrm{sm}^{-1}\right)$ is the canopy resistance, which is the reciprocal of canopy conductance $g c\left(g c=1 r c^{-1}\right)$.

On top of estimating ET as a sum of evaporation from moist soil, interception and transpiration, the daytime and nighttime ET were further computed separately [32,33]. Instead of using NDVI to compute the fraction of vegetation cover $(F c)$, they used the Fraction of Absorbed Photosynthetically Active Radiation (FPAR) as a surrogate of vegetation cover fraction, with another modification to the derivation of soil heat flux. Moreover, the model was modified by separating (i) dry and wet (interception) canopy surfaces, (ii) soil surface into saturated and moist surface, and (iii) improving stomatal conductance, aerodynamic resistance and boundary layer resistance estimates.

The core input variables used in this model are Tair, $R H$, land surface temperature $(L S T)$, surface emissivity $\left(\varepsilon_{s}\right)$, leaf area index $(L A I)$ and land surface albedo $(\alpha)$, and were used to derive intermediate inputs like net solar radiation (Rnet), vapour pressure deficit 
$(V P D)$, the slope of the saturated vapour - air temperature curve $(\Delta)$, the air and saturated air vapour pressures $\left(e, e_{s a t}\right)$ and the aerodynamic and surface resistances $\left(r_{a}, r_{s}\right)$.

\subsection{Uncertainty and Sensitivity Analysis}

Uncertainty and sensitivity analyses were performed on the PM-Mu to quantify input uncertainties and how these are propagated to the final ET uncertainties, and identify the inputs and parameters that are most important in modelling ET in a semi-arid environment. We assessed the uncertainty of each input variable, i.e., the direct measured variable uncertainty (core input), derived input variable uncertainty (intermediate variable) and remote-sensing-based input variable uncertainty using Type A and Type B uncertainty methods (see Section 2.3.1). The total uncertainty on the model simulations, i.e., model output uncertainty, was then evaluated by uncertainty propagation using the Gaussian uncertainty analysis method.

Based on the PM-Mu model, ET is defined as a function $(f)$ of meteorological point measurements of Tair and $R H$, and spatially explicit remote sensing estimates of LST, and land surface characteristics such as $L A I$, fraction of green vegetation cover $(F c) /$ fraction of photosynthetically active radiation $(F P A R), N D V I / E V I$ and surface emissivity $\left(\varepsilon_{s}\right)$, which are biome/or land cover characteristics defining parameters. Table 1 below summarises the core and intermediate inputs and parameters used in this study.

Table 1. Summary of the core inputs and their intermediate variables used in the equation of the PM model as modified by $\mathrm{Mu}$, et al. [32], Mu, et al. [33] (PM-Mu). The inputs used to estimate each variable are marked with an $\mathrm{x}$.

\begin{tabular}{cccccccc}
\hline & & \multicolumn{3}{c}{ Surface Resistance } & \multicolumn{3}{c}{ Aerodynamic Resistance } \\
\cline { 3 - 7 } Core Input & Rnet & $\mathbf{r}_{\mathbf{s}}{ }^{\text {wc }}$ & $\mathbf{r}_{\mathbf{s}}{ }^{\mathbf{t}}$ & $\mathbf{r}_{\mathbf{s}}{ }^{\text {tot }}$ & $\mathbf{r}_{\mathbf{a}}{ }^{\text {wc }}$ & $\mathbf{r}_{\mathbf{a}}{ }^{\mathbf{t}}$ & $\mathbf{r}_{\mathbf{a}}{ }^{\mathbf{s}}$ \\
\hline Tair & $\mathrm{x}$ & & & & $\mathrm{x}$ & $\mathrm{x}$ & \\
LST & $\mathrm{x}$ & & $\mathrm{x}$ & $\mathrm{x}$ & & & $\mathrm{x}$ \\
Tmin & $\mathrm{x}$ & & $\mathrm{x}$ & & & & \\
$\alpha$ & $\mathrm{x}$ & $\mathrm{x}$ & $\mathrm{x}$ & & $\mathrm{x}$ & & \\
LAI & & $\mathrm{x}$ & $\mathrm{x}$ & & $\mathrm{x}$ & $\mathrm{x}$ & $\mathrm{x}$ \\
$\varepsilon_{\mathrm{s}}$ & & & & & & &
\end{tabular}

The generic model can be presented as:

$$
E T=f\left(x_{1}, \ldots, x_{n}\right)
$$

where $x_{1}$ to $x_{n}$ represents the $n$ input variables and parameters of the PM-Mu model.

The change in ET, i.e., $\triangle E T$, resulting from errors and/or uncertainties in input variables $\left(\Delta x_{i}\right)$, is then expressed as:

$$
E T \pm \Delta E T=\left(x_{1} \pm \Delta x_{1}, \ldots, x_{n} \pm \Delta x_{n}\right)
$$

The study analysed the uncertainty and sensitivity of the PM-Mu input variables and outputs aimed at:

i. Estimating the uncertainty of model inputs and parameters, i.e., the meteorological and land surface characteristics, representing both point- and remote-sensingbased inputs;

ii. Propagating input uncertainties through to the ET model and computing output uncertainties;

iii. Estimating the sensitivity coefficients of the model inputs. 


\subsubsection{Core Input Variable Uncertainties}

The core inputs of the PM-Mu equation include relative humidity $(R H)$ and air temperature (Tair). We estimated the uncertainty of each core input variable as a combination of Type A and Type B uncertainties. In this study, where each measured input variable was a daily mean of 30-min recordings, we computed the Type $A\left(U_{A}\right)$ standard uncertainty of the meteorological inputs as the standard deviation of the daily mean:

$$
U_{A}\left(x_{i}\right)=\sqrt{\frac{\sum_{i=1}^{n}\left(x_{i}-\bar{x}_{i}\right)^{2}}{v}}
$$

where $x_{i}$ is the input value of the variable or parameter under consideration, $\bar{x}_{i}$ is the average value of the measured values calculated from the n number of independent observations and $v$ is the degrees of freedom equal to $n-1$.

Type B standard uncertainty $\left(U_{B}\right)$ was also computed for the meteorological input variables, based on the instrument manufacturer's published accuracies. The quoted accuracies of the measurement instruments are summarised in Table 2 . They were estimated using Equation (5):

$$
U_{B}\left(x_{i}\right)=\frac{a}{\sqrt{3}}
$$

where $a$ is the quoted accuracy specification from the manufacturer and includes calibration information from calibration certificates.

Table 2. Quoted accuracy of meteorological instruments used to measure air temperature (Tair) and relative humidity $(R H)$

\begin{tabular}{|c|c|c|c|c|}
\hline \multirow[b]{2}{*}{ Measurement } & \multicolumn{2}{|c|}{ Skukuza } & \multicolumn{2}{|c|}{ Welgegund } \\
\hline & Sensor & Quoted accuracy & Sensor & Quoted accuracy \\
\hline Temperature & $\begin{array}{c}\text { Campbell Scientific } \\
\text { HMP50 }\end{array}$ & $\begin{array}{c}0.4^{\circ} \mathrm{C} \text { at } 15^{\circ} \mathrm{C}, \\
0.5^{\circ} \mathrm{C} \text { at } 40^{\circ} \mathrm{C}, \\
0.8^{\circ} \mathrm{C} \text { at } 60{ }^{\circ} \mathrm{C} \\
\text { at } 20^{\circ} \mathrm{C} \\
\pm 3 \% 0 \text { to } 90 \% R H, \\
\pm 5 \% 90 \text { to } 98 \% R H\end{array}$ & $\begin{array}{c}\text { Vaisala WXT510 } \\
\text { meteorological station } \\
\text { (Helsinki, Finland) }\end{array}$ & $\begin{array}{c}0.3^{\circ} \mathrm{C} \text { at } 20^{\circ} \mathrm{C}, \\
0.4^{\circ} \mathrm{C} \text { at } 40^{\circ} \mathrm{C}, \\
0.7^{\circ} \mathrm{C} \text { at } 60^{\circ} \mathrm{C} \\
\text { at } 20^{\circ} \mathrm{C} \\
\pm 3 \% 0 \text { to } 90 \% R H, \\
\pm 5 \% 90 \text { to } 100 \% R H\end{array}$ \\
\hline
\end{tabular}
at the two observation sites.

For meteorological data inputs, the combined standard uncertainty was then estimated as:

$$
U_{C}\left(x_{i}\right)=\sqrt{\left(U_{A\left(x_{i}\right)}^{2}+U_{B\left(x_{i}\right)}^{2}\right)}
$$

The combined uncertainty was then converted to relative uncertainty for detailed comparison and analysis as follows:

$$
\text { Relative uncertainty }=\frac{U_{C}\left(x_{i}\right)}{\bar{x}_{i}} * 100
$$

\subsubsection{Remote-Sensing-Based Input Uncertainties}

In this study, we used the Moderate Resolution Imaging Spectroradiometer (MODIS) Terra/Aqua products as data inputs. The following MODIS products were used as inputs for this study: MOD11A1 LST and $\varepsilon s$, MOD15A2 LAI and MCD43A3 $\alpha$. These datasets were downloaded from the NASA Land Processes Distributed Active Archive Centre (LP DAAC) website using the USGS EarthExplorer platform (https: / / earthexplorer.usgs.gov/). These downloaded MODIS products were loaded onto ArcGIS together with the two flux tower GPS points. The values for the loaded points were then extracted from the MODIS products using the point extraction feature on ArcGIS software. These remotesensing-derived inputs have uncertainties due to several factors, including model algorithm 
structure and their input variables. The uncertainties of the remotely sensed input variables used in this study $(L S T, \varepsilon S, L A I, \alpha)$ were extracted mainly from their published Algorithm Theoretical Basis Documents (ATBD). Based on the quoted errors (Table 3), the uncertainties were then estimated using Equation (5). We give a short description of each variable and associated remote sensor below.

- $\quad$ Land surface temperature (LST) and surface emissivity $\left(\varepsilon_{s}\right)$ : these variables are essential in land surface-atmosphere studies, including the estimation of evapotranspiration and atmospheric water vapour. In our study, we used the MODIS-derived MOD11A1 V006 product, which is generated from the thermal infrared channels 31 (10.78 to $11.28 \mu \mathrm{m})$ and 32 (11.77 to $12.27 \mu \mathrm{m})$ using the physically-based day-night split-window algorithm by [37]. The uncertainties associated with these products are extensively discussed in the MODIS Land-Surface Temperature ATBD [38-40]. They indicate an absolute error of $1 \mathrm{~K}$ for $L S T$, which can increase up to $5 \mathrm{~K}$ in arid regions. For surface emissivity, the absolute accuracy is reported to be 0.02 .

- $\quad$ Land surface albedo $(\alpha)$ : defined as a dimensionless characteristic of the soil-plant canopy system representing the fraction of total solar energy reflected by the surface, it is expressed as the ratio of the radiant energy scattered upward by a surface in all directions to that received from all directions, integrated over the wavelengths of the solar spectrum. Surface albedo is one of the key geophysical parameters that control the surface energy budget. The MODIS bi-directional reflectance distribution function (BRDF) and albedo product (MCD43A3 version VOO6) was used in this study. This product was derived using a kernel-driven semi-empirical BRDF model using the RossThick-LiSparse kernel functions for characterising isotropic, volume and surface scattering [41-43]. Studies have given an absolute accuracy of 0.02 to 0.05 as a requirement for climate modelling $[44,45]$, with other validation studies $[46,47]$ reporting errors falling within the 0.02 accuracy.

- Leaf Area Index ( $L A I)$ : defined as the total one-sided green leaf area per unit ground surface area, it is also dimensionless. This variable measures the total amount of leaf material in an ecosystem. It is used in the estimation of biogeochemical processes like photosynthesis, evapotranspiration and net primary production. The MOD15A2 V005 product used in this study was derived using the three-dimensional radiative transfer (3D RT) model $[48,49]$. The product ATBD reports the accuracy of the LAI product at 0.2 [48]. Furthermore, a review by Fang, et al. [50] summarises the uncertainties of MODIS, CYCLOPES and GLOBCARBON LAI products under different biomes, showing a relative uncertainty of 0.26 in the savanna biome for the MODIS product.

Table 3. Quoted accuracy of remote sensing inputs at the two observation sites.

\begin{tabular}{cccc}
\hline & Error Values & Units & Reference \\
\hline LST & \pm 3.5 & $\mathrm{~K}$ & Hulley, et al. [39] \\
$\varepsilon_{\mathrm{S}}$ & \pm 0.02 & - & Wan [38] \\
LAI & \pm 0.2 & - & Knyazikhin, et al. [48] \\
$\alpha$ & \pm 0.02 & - & Strahler, et al. [51] \\
\hline
\end{tabular}

\subsubsection{Intermediate Input Uncertainty}

For intermediate inputs that were derived from the core input variables, like net radiation and surface and aerodynamic resistances, the standard uncertainties were estimated as combined standard uncertainties of their inputs. The Gaussian error propagation method, which describes how the uncertainties in the variables $x$ and $y$ propagate into a function $f(x, y)$ and assumes that the model inputs are uncorrelated, was used, as shown in Equation (8):

$$
U_{C}\left(Y_{i}\right)=\sqrt{\sum_{i=1}^{n}\left(\left(\frac{\partial Y_{i}}{\partial x_{i}}\right)^{2} *\left(U_{C}\left(x_{i}\right)\right)^{2}\right)}
$$


where $\frac{\partial Y_{i}}{\partial x_{i}}$ is the partial derivative of $y$, which is the output variable, with reference to input variables $x_{i}$ to $x_{n}$, also called sensitivity coefficient.

Each estimated input variable uncertainty was also propagated to the final ET output uncertainty using Equation (8).

\subsection{Sensitivity Analysis}

One of the aims of SA is to identify and rank input variables according to their importance in modelling a particular phenomenon. This is done to identify the input variables that require a more accurate measurement to reduce model output variance to a minimum. The sensitivity of the PM-Mu estimated daily ET was determined by varying one input variable at a time within $\pm 20 \%$ ranges. First, ET was computed with the initial input variables, then one variable was perturbed by $5 \%$ within $\pm 20 \%$ whilst the rest of the inputs were held constant every day for the whole year of 2012 and the new ET values were recorded. Then, the sensitivity coefficient, $S$, was computed using Equation (9), after which an overall average was calculated:

$$
S_{i}=\left(\frac{Y_{i}-Y_{0}}{Y_{0}}\right) * 100
$$

where $Y_{i}$ is the ET recorded when you vary one variable at a time at each percentage step, and $Y_{0}$ is the initial ET value.

\section{Results}

Uncertainty analysis gives a range of values likely to enclose the true value, and thus the confidence of the modelled values, and includes all possible sources of error. Meanwhile, sensitivity analysis ranks the input variables according to their sensitivity to errors in a model. In our study, we quantified the uncertainty of the PM-Mu ET model input variables at two FLUXNET sites in semi-arid ecosystems, Skukuza and Welgegund, and analysed how these propagated through to the model's final output uncertainty.

\subsection{Core Input Variables Uncertainty}

Figure 2 illustrates the annual variations of Tair, bound with the absolute uncertainties for the two study areas. With a mean annual Tair of $24 \pm 3.57^{\circ} \mathrm{C}$, the absolute standard uncertainty was $1.5 \pm 0.7^{\circ} \mathrm{C}$ for Skukuza. Welgegund's mean annual Tair was $20 \pm 5.2^{\circ} \mathrm{C}$, with the absolute standard uncertainty similar with that of Skukuza, with an average of $1.5 \pm 0.42{ }^{\circ} \mathrm{C}$. Meanwhile, this translated to Tair's relative uncertainty, between 0.5 and $7.6 \%$, with an average of $3.1 \pm 1.5 \%$ for Skukuza, and it varied between 0.9 and $10.6 \%$ with a mean of $4.0 \pm 1.7 \%$ for Welgegund.

As shown in Figure 3, the annual daily average $R H$ varied between 34 and $94 \%$ during the same period for Skukuza, and the mean absolute uncertainty was $5 \pm 1.5 \%$. This result was converted to an average relative uncertainty of $10 \pm 3.5 \%$. On the other hand, Welgegund's annual daily average $R H$ ranged between 13 and $98 \%$, and the mean absolute uncertainty was $6 \pm 1.9 \%$, while the relative uncertainty was $14.2 \pm 5.4 \%$.

Relative uncertainties of both Tair and $R H$ have strong seasonal variability, with relative uncertainties being higher during the drier months of the year, i.e., between April and September, compared to the wet months. During this period, daily temperatures tend to be highly variable throughout the day, hence the high Type A standard uncertainty. Furthermore, there was much less variation in Tair's relative uncertainty between the two sites compared to $R H^{\prime}$ 's relative uncertainty. 


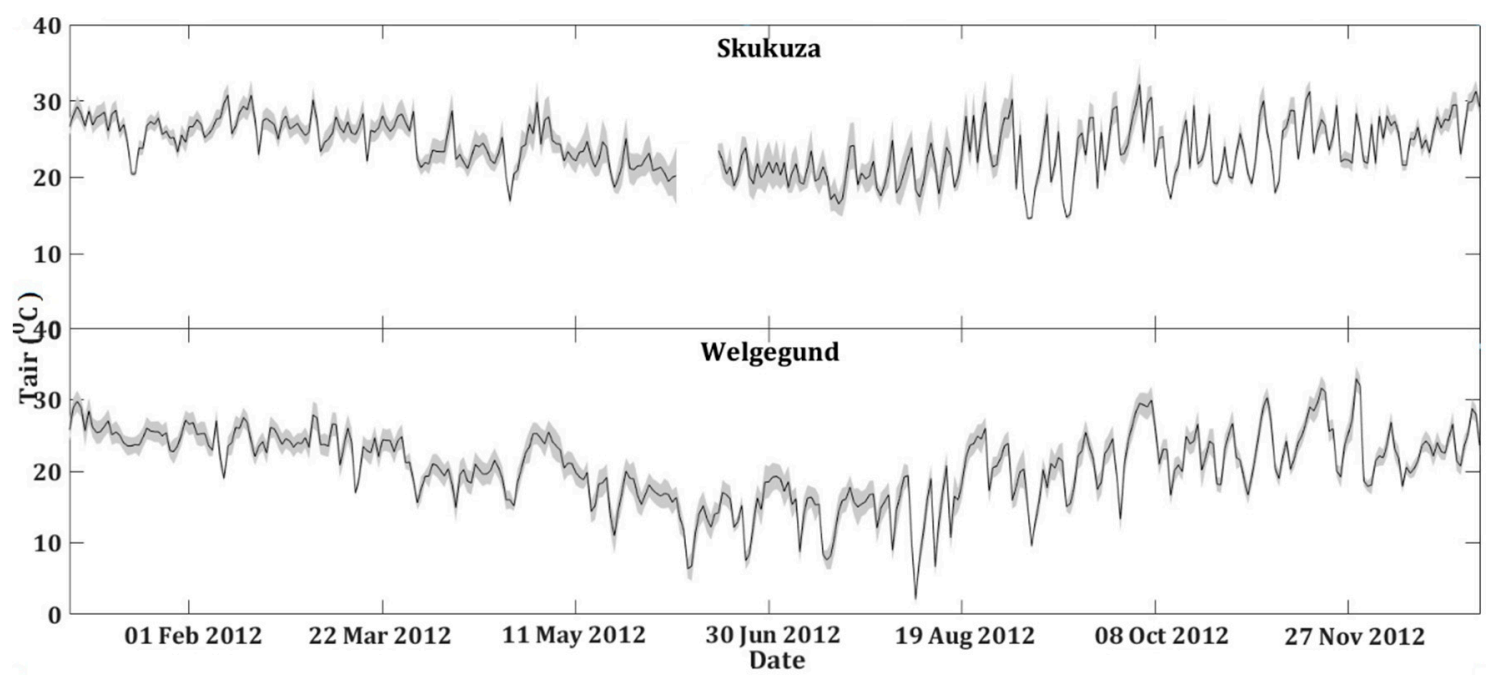

Figure 2. Daily average air temperature of year 2012 for the two study sites. The grey bounds indicate the absolute uncertainties, which were added as standard deviations.

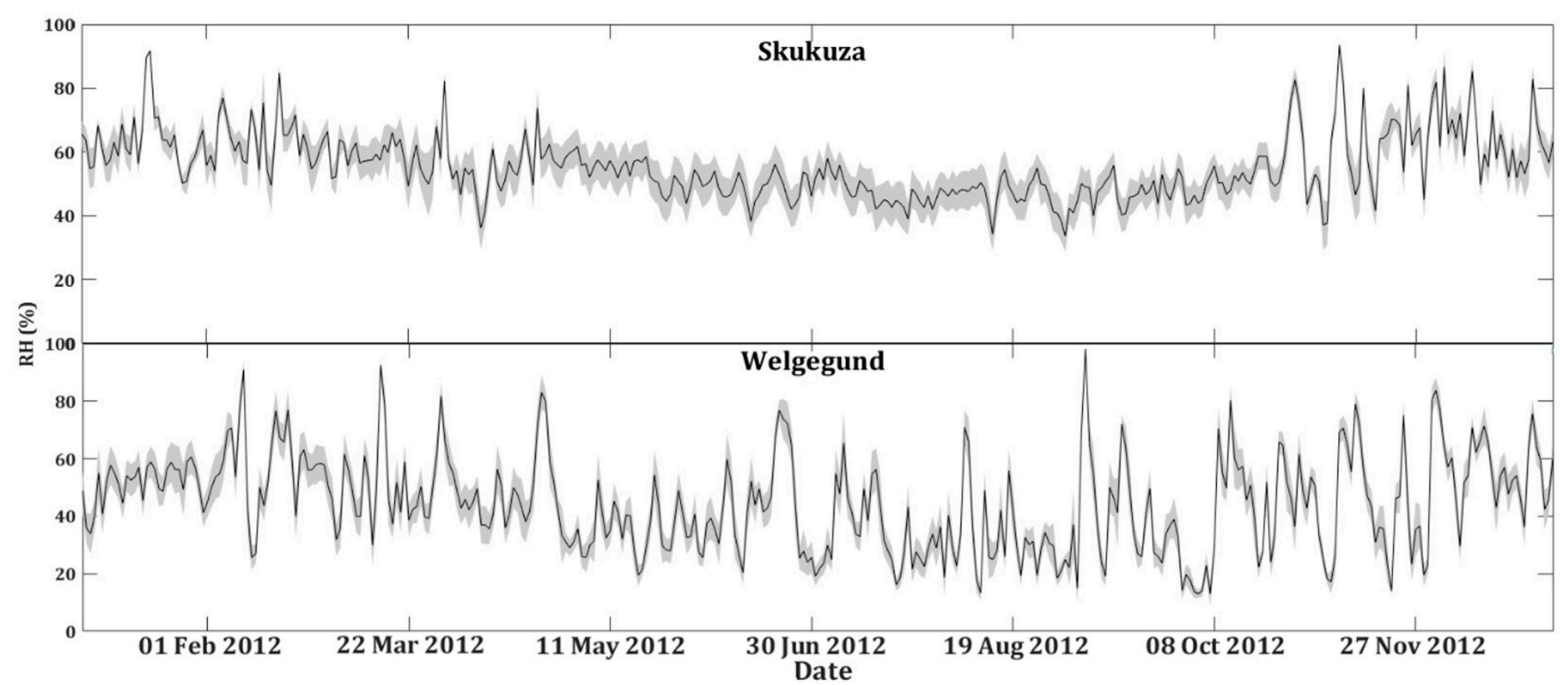

Figure 3. Daily average relative humidity of year 2012 for the two study sites. The grey bounds indicate the absolute uncertainties, which were added as standard deviations.

\subsection{Intermediate Input Uncertainty}

This subsection reports how the core input uncertainties estimated above were propagated onto the ET intermediate inputs, i.e., Rnet and the aerodynamic and surface resistances.

\subsubsection{Net Radiation Uncertainty}

Net radiation (Rnet) estimation depends on a number of atmospheric and land surface variables, including $\alpha, \varepsilon_{\mathrm{s}}, \varepsilon_{\mathrm{a}}, L S T$ and Tair. The overall relative uncertainty of Rnet was $4.0 \pm 0.6 \%$ of the estimated $558.0 \pm 105.2 \mathrm{Wm}^{-2}$ daytime Rnet in Skukuza, whereas for Welgegund, a $2.8 \pm 0.8 \%$ relative uncertainty was reported for the derived $556.4 \pm 127.7 \mathrm{Wm}^{-2}$ Rnet. As summarised in Table 4, for Skukuza, a mean relative air temperature (Tair) uncertainty of $3.1 \%$ was associated with relative Rnet uncertainties of $23.28 \pm 9.85 \%$ of the total Rnet uncertainty, whereas a land surface temperature (LST) error of $3.5 \mathrm{~K}$ contributed $59.31 \pm 12.87 \%$ to the total uncertainty, which was the highest contributor to Rnet uncertainty. The surface emissivity $\left(\varepsilon_{\mathrm{s}}\right)$ error of 0.02 contributed an Rnet uncertainty between 4 
and $7 \mathrm{Wm}^{-2}$, while the albedo $(\alpha)$ uncertainty contributed to an average $2.8 \pm 0.42 \mathrm{Wm}^{-2}$ Similar results were found for Welgegund, where a mean relative Tair uncertainty of $4 \%$ resulted in an Rnet relative uncertainty of $30.25 \pm 10.23 \%$, whereas $89.42 \pm 22.07 \%$ of the total Rnet uncertainty was attributed to an LST error of $3.5 \mathrm{~K}$, showing that it was the highest source of uncertainty in Rnet estimation. $\varepsilon_{s}$ and $\alpha$ contributed mean relative uncertainties of $38.81 \pm 9.43$ and $22.06 \pm 10.31 \%$, respectively.

Table 4. Contribution of each input variable uncertainty to the total net radiation (Rnet) uncertainty.

\begin{tabular}{ccccc}
\hline & \multicolumn{2}{c}{ Skukuza } & \multicolumn{2}{c}{ Welgegund } \\
\cline { 2 - 5 } & Mean & Standard Deviation & Mean & Standard Deviation \\
\hline Total uncertainty & 22.12 & 5.58 & 14.73 & 5.16 \\
\% Tair & 23.28 & 9.85 & 30.25 & 10.23 \\
$\%$ LST & 59.31 & 12.87 & 89.42 & 22.07 \\
$\% \alpha$ & 13.13 & 0.42 & 22.06 & 10.31 \\
$\% \varepsilon_{\mathrm{S}}$ & 25.76 & 5.44 & 38.81 & 9.43 \\
\hline
\end{tabular}

\subsubsection{Aerodynamic and Surface Resistances}

In the estimation of wet canopy evaporation, the aerodynamic resistance to evaporated water on the wet canopy surface $\left(r_{a}{ }^{w c}\right)$ is a function of Tair, LAI and $R H$ (in the form of wet surface fraction (Fwet)), whereas the surface resistance to evaporated water on the wet canopy $\left(r_{s}{ }^{w c}\right)$ is a function of LAI and $R H$. Further, in plant transpiration estimation, the aerodynamic resistance to water vapour from a dry canopy surface $\left(r_{a}^{t}\right)$ is a function of Tair only; and the canopy resistance to transpired water $\left(r_{s}{ }^{t}\right)$ is estimated from LST, LAI, Tmin and $R H$. In the computation of soil evaporation, both the surface $\left(r_{s}{ }^{t o t}\right)$ and aerodynamic resistances $\left(r_{a}^{s}\right)$ to water vapour from the soil surface are a function of LST and VPD (which is indirectly $R H$ ).

Our results, as illustrated in Table 5 (only the standard uncertainties for resistances are shown here), show that the mean standard uncertainties for $\mathrm{r}_{\mathrm{a}}{ }^{\mathrm{wc}}$ were $0.0011 \mathrm{~ms}^{-1} \pm 6.25 \%$ and $0.001 \mathrm{sm}^{-1} \pm 0.17 \%$ for Skukuza and Welgegund, respectively. Of the total standard $\mathrm{r}_{\mathrm{a}}{ }^{\mathrm{wc}}$ uncertainty, Tair contributed the highest uncertainty of average $91 \pm 5.0 \%$ and $96.02 \pm 16.54 \%$, with low contributions from the LAI and RH uncertainties for Skukuza and Welgegund, respectively. Meanwhile, $\mathrm{r}_{\mathrm{s}}{ }^{\mathrm{wc}}$ standard uncertainties were an average $10.34 \pm 10.0 \mathrm{sm}^{-1}$ and $18.02 \pm 19.0 \mathrm{sm}^{-1}$, respectively, with $\mathrm{RH}$ uncertainty contributing most to the total $\mathrm{r}_{\mathrm{s}}{ }^{\mathrm{wc}}$ uncertainty (approximately $80 \%$ ), on both sites.

Table 5. Aerodynamic and surface resistance standard uncertainties and contributions to each component of ET uncertainty.

\begin{tabular}{|c|c|c|c|c|c|c|c|c|}
\hline & \multicolumn{4}{|c|}{ Skukuza } & \multicolumn{4}{|c|}{ Welgegund } \\
\hline & \multicolumn{2}{|c|}{$\begin{array}{c}\text { Aerodynamic } \\
\text { Resistance }\end{array}$} & \multicolumn{2}{|c|}{$\begin{array}{c}\text { Surface } \\
\text { Resistance }\end{array}$} & \multicolumn{2}{|c|}{$\begin{array}{c}\text { Aerodynamic } \\
\text { Resistance }\end{array}$} & \multicolumn{2}{|c|}{ Surface Resistance } \\
\hline & Mean & $\begin{array}{l}\text { Standard } \\
\text { Deviation }\end{array}$ & Mean & $\begin{array}{l}\text { Standard } \\
\text { Deviation }\end{array}$ & Mean & $\begin{array}{l}\text { Standard } \\
\text { Deviation }\end{array}$ & Mean & $\begin{array}{l}\text { Standard } \\
\text { Deviation }\end{array}$ \\
\hline $\begin{array}{l}\text { Interception } \\
\text { Evaporation }\end{array}$ & $1.1 \times 10^{-3}$ & $3.5 \times 10^{-4}$ & 10.34 & 10.07 & $1 \times 10^{-3}$ & $3 \times 10^{-4}$ & 18.02 & 18.96 \\
\hline Transpiration & $1.6 \times 10^{-3}$ & $7 \times 10^{-4}$ & 21.68 & 19.68 & $1.5 \times 10^{-3}$ & $4.3 \times 10^{-4}$ & 30.71 & 26.92 \\
\hline Soil evaporation & $3.8 \times 10^{-3}$ & $2.4 \times 10^{-4}$ & 0.53 & 0.04 & $3.8 \times 10^{-3}$ & $2.5 \times 10^{-4}$ & 0.51 & 0.06 \\
\hline
\end{tabular}

In the estimation of $r_{a}{ }^{t}$ standard uncertainty, the values ranged between 0.00019 and $0.0038 \mathrm{sm}^{-1}$, and 0.00031 and $0.0032 \mathrm{sm}^{-1}$ (low average relative uncertainties of $0.81 \pm 0.36 \%$ and $0.84 \pm 0.22 \%$ ) for Skukuza and Welgegund, respectively. These low values indicate that Tair uncertainties have the least effect in the estimation of $r_{a}{ }^{t}$ uncertainty. Total standard $r_{s}{ }^{t}$ uncertainty ranged from 0 to $90 \mathrm{sm}^{-1}$ (mean relative uncertainty of $8.82 \pm 2.71 \%$ ) for Skukuza; whereas for Welgegund, it was between 20 and $146 \mathrm{sm}^{-1}$, 
(average relative uncertainty of $8.4 \pm 1.7 \%$ ). The $\mathrm{r}_{\mathrm{a}}{ }^{\mathrm{s}}$ relative uncertainties were on average around $2 \%$ for both sites. Finally, $r_{s}{ }^{\text {tot }}$ standard uncertainty ranged from 0.45 to $0.73 \mathrm{sm}^{-1}$, and 0.35 to $0.77 \mathrm{sm}^{-1}$, for Skukuza and Welgegund, respectively, an average $1 \%$ relative uncertainty for both sites. Of the total uncertainty, LST uncertainty contributed the most of the two input variables with an average of $58 \%$ and $63 \%$, whereas $5.25 \%$ of the total $r_{S}{ }^{\text {tot }}$ uncertainty was attributed to VPD uncertainty, for Skukuza and Welgegund, respectively.

\subsubsection{Uncertainty in Evapotranspiration}

The final estimate of ET uncertainty is a result of uncertainties propagated from the measured and remote sensing input variables, through intermediate parameters, up to the final ET uncertainty. The standard uncertainty was computed for each ET component, i.e., evaporation from intercepted rainfall (wet canopy), transpiration and soil evaporation, and ultimately combined to give the total ET uncertainty.

In Skukuza (Table 6), of the $0.038 \mathrm{mmday}^{-1}$ wet canopy evaporation standard uncertainty, $r_{s}{ }^{w c}$ uncertainty contributed the highest with $21.46 \pm 5.97 \%$, with VPD also having a considerable impact of $6.37 \pm 1.45 \%$ while the rest of the inputs $\left(r_{a}{ }^{w c}, F c\right.$ and Fwet)

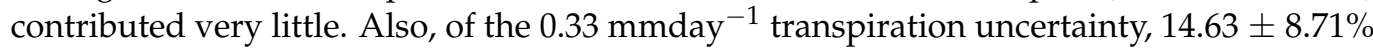
of it was attributed to VPD uncertainty and $9.64 \pm \%$ to Fwet uncertainty. Wet soil evaporation uncertainty of $0.11 \mathrm{~mm}^{-2}$ day $^{-2}$ was made of $12.3 \%$ of Fwet uncertainty, $9.7 \%$ of $V P D$ uncertainty, and very low contributions from the rest of the inputs. Lastly, VPD uncertainty contributed the highest to the potential soil evaporation uncertainty of $21.5 \%$.

Table 6. Contribution of core and intermediate input variable relative uncertainties to each component of ET uncertainty for Skukuza.

\begin{tabular}{|c|c|c|c|c|c|c|c|c|}
\hline & \multicolumn{2}{|c|}{ Transpiration } & \multicolumn{2}{|c|}{ Interception Loss } & \multicolumn{2}{|c|}{$\begin{array}{l}\text { Potential Soil } \\
\text { Evaporation }\end{array}$} & \multicolumn{2}{|c|}{$\begin{array}{c}\text { Wet Soil } \\
\text { Evaporation }\end{array}$} \\
\hline & Mean & $\begin{array}{l}\text { Standard } \\
\text { Deviation }\end{array}$ & Mean & $\begin{array}{l}\text { Standard } \\
\text { Deviation }\end{array}$ & Mean & $\begin{array}{l}\text { Standard } \\
\text { Deviation }\end{array}$ & Mean & $\begin{array}{l}\text { Standard } \\
\text { Deviation }\end{array}$ \\
\hline $\begin{array}{l}\text { Total standard uncertainty } \\
\qquad\left(\text { mmday }^{-1}\right)\end{array}$ & 0.33 & 0.41 & 0.038 & 0.14 & 0.89 & 0.34 & 0.12 & 0.22 \\
\hline$\%$ RH (VPD) & 14.63 & 8.71 & 6.37 & 1.45 & $(21.49)$ & $(13.37)$ & $(9.71)$ & $(2.66)$ \\
\hline$\%$ FC $\left(1-F_{C}\right)$ & 1.36 & 1.02 & 0.67 & 0.28 & $(0.85)$ & $(0.38)$ & & \\
\hline \% Fwet (1-Fwet) & 9.64 & 3.31 & 0.97 & 0.05 & $(2.69)$ & (5.19) & 12.92 & 4.49 \\
\hline$\% \mathrm{r}_{\mathrm{a}}^{\mathrm{s}}$ & & & & & 1.93 & 0.8 & 2.02 & 0.74 \\
\hline$\% \mathrm{r}_{\mathrm{s}}^{\mathrm{t}}{ }^{\mathrm{t}}$ & & & & & 1.29 & 0.49 & 1.25 & 0.45 \\
\hline$\% \mathrm{r}_{\mathrm{a}}^{\mathrm{t}}$ & 0.89 & 0.08 & & & & & & \\
\hline$\% r_{s}^{t}$ & 2.42 & 5.03 & & & & & & \\
\hline$\% r_{a}{ }^{w C}$ & & & 0.97 & 0.05 & & & & \\
\hline$\% r_{s}{ }^{W c}$ & & & 21.46 & 5.97 & & & & \\
\hline
\end{tabular}

In Welgegund (Table 7), ET estimation was only the sum of the potential soil evaporation and transpiration, and so were the uncertainties, since wet soil evaporation and wet canopy evaporation gave zero values and did not contribute to the final ET. The potential soil evaporation standard uncertainty of 1.05 mmday $^{-1}$ was mainly a result of $V P D$, which contributed $46.11 \%$, while other inputs had very low contributions. The transpiration standard uncertainty of 0.13 mmday $^{-1}$ mostly resulted from the VPD, that contributed $26.93 \pm 15.13 \%$, while other inputs had relatively low contributions.

The total ET mean relative uncertainty for Skukuza was $76.19 \pm 30.82 \%$. The total uncertainty for Welgegund was similar to that of Skukuza, with a mean relative uncertainty of $81.1 \pm 17.57 \%$. In both sites, the highest uncertainty was attributed to soil evaporation, which contributed $76.74 \pm 19.13 \%$ of the $1.38 \pm 0.51$ mmday $^{-1}$ in Skukuza, and $90.93 \pm 32.46 \%$ of the $1.62 \pm 0.36 \mathrm{mmday}^{-1}$ in Welgegund; subsequently, plant transpiration uncertainty presented a mean of $23.06 \pm 18.83 \%$ and $18.21 \pm 18.62 \%$ for Skukuza and 
Welgegund, respectively. On both sites, the wet canopy evaporation uncertainty was very low, which corresponded with this portion of evapotranspiration.

Table 7. Contribution of core and intermediate input variable relative uncertainties to each component of evapotranspiration (ET) uncertainty for Welgegund.

\begin{tabular}{ccccc}
\hline & \multicolumn{2}{c}{ Transpiration } & \multicolumn{2}{c}{ Potential Soil Evaporation } \\
\cline { 2 - 5 } & Mean & $\begin{array}{c}\text { Standard } \\
\text { Deviation }\end{array}$ & Mean & $\begin{array}{c}\text { Standard } \\
\text { Deviation }\end{array}$ \\
\hline Total Uncertainty & 0.13 & 0.28 & 1.05 & 0.29 \\
$\%$ RH (VPD) & 26.93 & 15.13 & $(46.11)$ & $(53.05)$ \\
$\%$ Fc (1-Fc) & 3.85 & 3.10 & $(1.27)$ & $(0.81)$ \\
$\%$ Fwet (1-Fwet) & 0 & 0 & 0 & 0 \\
$\% \mathrm{r}_{\mathrm{a}}{ }^{\mathrm{s}}$ & & & 1.97 & 0.46 \\
$\% \mathrm{r}_{\mathrm{s}}{ }^{\text {tot }}$ & & & & 0.25 \\
$\% \mathrm{r}_{\mathrm{s}}{ }^{\mathrm{t}}$ & 0.87 & 0.12 & & \\
$\% \mathrm{r}^{\mathrm{s}}$ & 8.98 & 1.67 & & \\
\hline
\end{tabular}

\subsection{Sensitivity of PM-Mu Model to Core Input Variables}

A sensitivity assessment of the ET output to input variables was done on the PM-Mu model to determine which input variable contributes the most to ET output variation. The percentage change in ET with respect to a percentage change in input variables at the study sites is summarised in Table 8 and illustrated in Figure 4.

Table 8. Sensitivity of ET to input variables.

\begin{tabular}{|c|c|c|c|c|c|c|c|}
\hline \multirow{2}{*}{ Station } & \multirow{2}{*}{$\begin{array}{c}\text { Input } \\
\text { Variables }\end{array}$} & \multicolumn{6}{|c|}{$\%$ Change in ET with Respect to \% Change in Input Variables } \\
\hline & & -20 & -10 & -5 & 5 & 10 & 20 \\
\hline \multirow{6}{*}{ Skukuza } & Tair & & -92.25 & -64.80 & 38.60 & & \\
\hline & LST & & 55.08 & 39.56 & -50.56 & -77.45 & \\
\hline & $\mathrm{RH}$ & -0.57 & -0.30 & -0.16 & 0.17 & 0.35 & 0.75 \\
\hline & $\varepsilon a$ & & 12.06 & 6.03 & -6.03 & -12.06 & \\
\hline & LAI & 1.28 & 0.47 & 0.19 & -0.12 & -0.16 & -0.02 \\
\hline & $\alpha$ & 6.16 & 3.08 & 1.54 & -1.54 & -3.08 & -6.16 \\
\hline \multirow{6}{*}{ Welgegund } & Tair & & -84.17 & -47.71 & 51.12 & 93.29 & \\
\hline & LST & & 84.75 & 44.15 & -57.83 & -63.15 & \\
\hline & $\mathrm{RH}$ & -0.37 & -0.19 & -0.10 & 0.10 & 0.20 & 0.43 \\
\hline & $\varepsilon \mathrm{a}$ & & 9.42 & 4.69 & -4.69 & -9.38 & \\
\hline & LAI & 0.50 & 0.12 & 0.03 & 0.03 & 0.13 & 0.48 \\
\hline & $\alpha$ & 5.00 & 2.50 & 1.25 & -1.25 & -2.50 & -5.00 \\
\hline
\end{tabular}

In the savanna biome, the PM-Mu model was mainly sensitive to LST and Tair. A change of $-10 \%$ and $-5 \%$ in Tair resulted in a $92 \%$ and $65 \%$ ET decrease, respectively, whereas an increase of 5\% increased ET by 39\%. In contrast, an LST decrease by the same values resulted in ET increasing by 55\% and 40\%, respectively. On the other hand, an LST increase of $5 \%$ and $10 \%$ resulted in an ET decrease of $51 \%$ and $77 \%$, respectively. $\varepsilon_{a}$ changes from $-20 \%$ to $0 \%$ gave an ET increase of $+10 \%$, and generated an ET increase and decrease of $12 \%$, respectively, and $\alpha$ changes of $-20 \%$ to $+20 \%$ decreased ET by between 6.16 and $-6.16 \%$. ET had the lowest sensitivities to $R H$ and $L A I$, with the computed parameter variations producing ET variations mostly inferior to $3 \%$.

The grassland biome results were quite comparable to the savanna biome results, and ET was again mostly sensitive to Tair and LST. The percentage change in ET in relation to Tair decreases of $-10 \%$ and $-5 \%$ were $-84 \%$ and $-48 \%$, while an increase of the same magnitudes showed an increase of 51\% and 93\%, respectively. Similarly, an LST decrease of the same magnitudes showed that ET increased by $85 \%$ and $44 \%$, respectively, and an increase of $5 \%$ and $10 \%$ resulted in an ET decrease of $58 \%$ and $63 \%$, respectively. ET was least sensitive to $R H, L A I$ and $\alpha$, with ET variations generally below $2.5 \%$. 


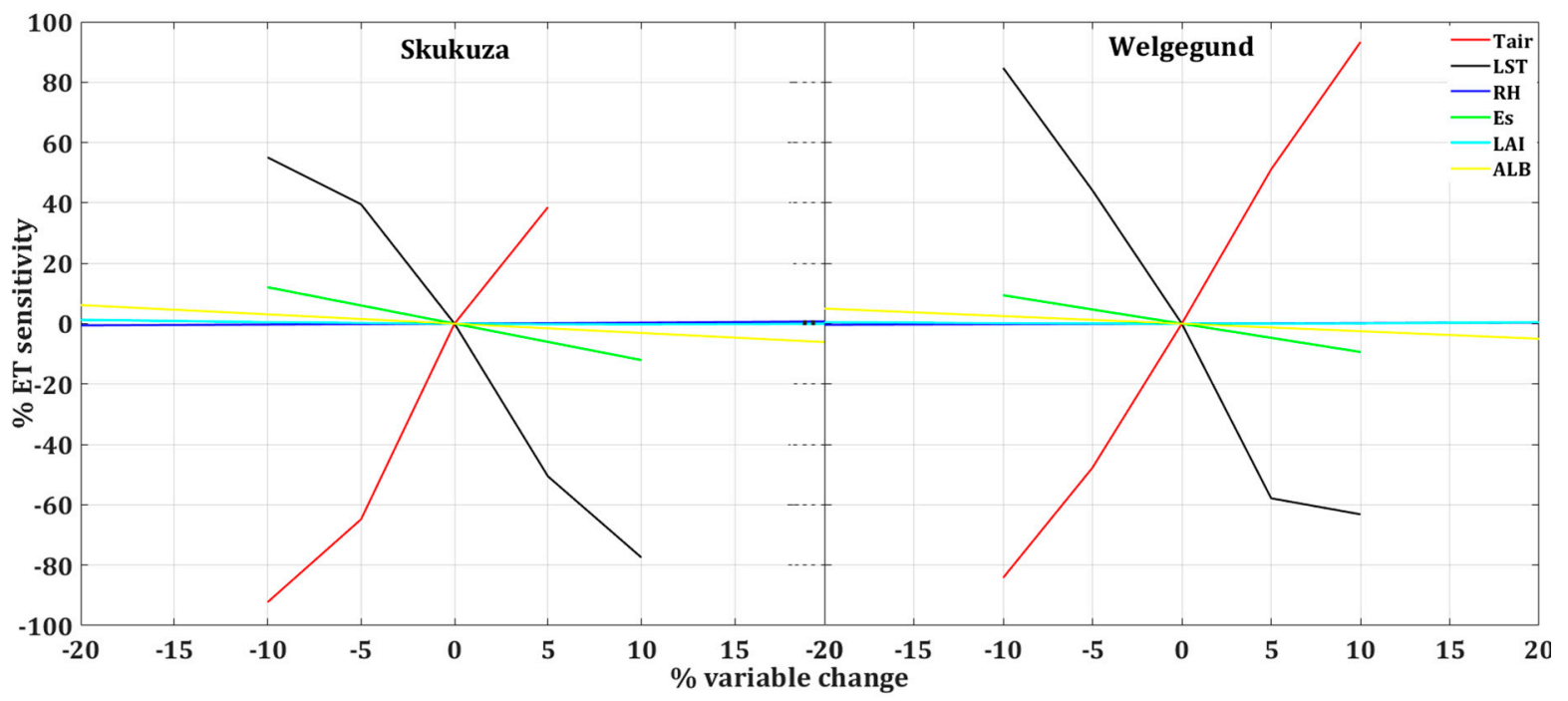

Figure 4. Sensitivity of the PM-Mu ET model to input variables.

\section{Discussion}

In this study, we evaluated how input variable uncertainty was propagated in the PM-Mu algorithm to the final ET uncertainty, along with the analysis of the sensitivity of the ET output to the different input variable uncertainties. Our study only concentrated on the uncertainty associated with the input variables including uncertainty propagation, and not on the model algorithms used to compute the intermediate variables and the final ET product.

The measured meteorological input variable uncertainties were estimated as a combination of Type A and B uncertainties, whereas for the remote-sensing-based inputs, values from the literature were used to compute Type B uncertainties. Another essential assumption made was that there is no correlation between the inputs variables. This, in reality, might not be fully true, an example being the possible relationship between Tair and $R H$. A sensitivity analysis of ET to both the measured and remote sensing estimated input variables was also conducted.

\subsection{Input Variable and Parameter Uncertainty \\ 4.1.1. Core Inputs}

The mean absolute standard uncertainties for air temperature (Tair) were within similar ranges for the two sites, i.e., $1.5 \pm 0.7^{\circ} \mathrm{C}$ and $1.5 \pm 0.42^{\circ} \mathrm{C}$, for Skukuza and Welgegund, respectively, with the variable showing slight seasonal uncertainty variation during the year. The cooler, drier season exhibited higher relative uncertainties compared with the hotter, wetter season on both sites. This is explained by high diurnal temperature ranges, and hence the high Type A standard uncertainties during the dry, cooler months. In contrast, relative humidity's $(R H)$ absolute standard uncertainty was $5 \pm 1.5 \%$ for Skukuza, and $6 \pm 1.9 \%$ for Welgegund, showing a rather lower variability throughout the year compared to Tair, especially for Skukuza. This was probably due to more stable $R H$ readings throughout the day, resulting in less variation in the estimated Type A uncertainty. Welgegund's $R H$ relative uncertainties were substantially higher than Skukuza's uncertainties, indicating a higher diurnal variation of $R H$ measurements at this site compared to the Skukuza site.

Our results are consistent with the ranges reported in other studies that have been conducted, albeit for different purposes. In most cases, Tair and $R H$ uncertainties have been evaluated simultaneously. For instance, ascertained Muniz, et al. [52] the standard uncertainty of air temperature and relative humidity measured by thermography and found a standard Tair uncertainty of between 0 and $2{ }^{\circ} \mathrm{C}$, and 0 and $5 \%$ for $R H$, in their study to ascertain the uncertainty of air temperature measured by thermography. In their 
case, though, they only considered Type B uncertainties, whereas we took into account Type A uncertainty, which is the variation of temperature over time. In addition, Lin and Hubbard [53] reported that the uncertainty of derived dewpoint temperature ranged from 1.8 to $3.3^{\circ} \mathrm{C}$. Comparing our results with other studies, like the ones discussed above, is a challenge because of the different metrics used in each study.

It is important to have an understanding of the uncertainties associated with the remote sensing products that are used in simulating ET, as shown in this study. These uncertainties are normally estimated and included in the ATB documents, with further research being carried out per biome. For example, the absolute quoted accuracy for LST is $1 \mathrm{~K}$ and 0.02 for $\varepsilon s$, in the Modis ATBD document [39]. However, these accuracies vary with land cover type and the type of uncertainties included in the estimations [54] and should be investigated in detail.

\subsubsection{Intermediate Data Components}

The core input variable uncertainties had varying effects on the uncertainties of intermediate parameters like net solar radiation, and the aerodynamic and surface resistances. There was little variation in Rnet uncertainty between the grassland and savanna sites, with the relative uncertainties modelled at $4 \%$ and $3 \%$ for Skukuza and Welgegund, respectively. Our results showed that on both sites, LST uncertainty contributed the most to the Rnet uncertainty, with $\varepsilon_{s}$ and Tair uncertainties also contributing meaningfully to the Rnet uncertainty. Contrasting with other studies, our total Rnet uncertainties are much different. For example, we recorded much lower Rnet uncertainties than those reported by Mira, et al. [55], who reported overall uncertainties of between 15\% and 20\% in varying sites of rainfed to irrigated meadows and crops in the Mediterranean region of the Rhône Valley, in Southeastern France. They also found that the main contribution to the total uncertainty was equally distributed between the measured incoming short and longwave radiations (at 5\% and $8 \%$, respectively), with $L S T$ contributing the least uncertainty.

The aerodynamic resistance $\left(r_{a}{ }^{w c}, r_{a}{ }^{t}, r_{a}{ }^{s}\right)$ relative uncertainties were consistent at an average of $0.8,0.5$ and $2 \%$, respectively, throughout the year, at both sites. Considering these low uncertainties, their contribution to the ET uncertainties was also low. These results concur with the findings of Ershadi, et al. [56], who also showed that aerodynamic resistances play a relatively minor role in ET estimation in the PM model. Furthermore, it has been shown that changes in the parameterisation of aerodynamic resistance in the PM model produce minor improvements to the model output $[57,58]$. Our results show that in comparison to the aerodynamic resistance uncertainties, relative surface resistance uncertainties were quite high. Given that surface resistances $\left(r_{s}{ }^{w c}, r_{s}{ }^{t}, r_{s}{ }^{t o t}\right)$ are a critical parameterisation in ET estimation, the corresponding uncertainties also have a noteworthy impact on standard uncertainties of ET. This was also reported by Ershadi, et al. [56], who determined that surface resistance parameterisation substantially affects PM model performance.

\subsubsection{Uncertainty in PM-Mu Evapotranspiration Estimation}

The final ET uncertainty is a product of all the input variable uncertainties that were propagated through the PM-Mu model. In our study, we only investigated the uncertainty associated with the input variables, and not with the algorithms used to compute the intermediate inputs and the final ET model. Soil evaporation uncertainty contributed the most to the final ET uncertainty in our study areas, with wet canopy evaporation uncertainty contributing slightly less.

In both biomes, our results show that $R H$ uncertainty, including input variables and parameters derived from $R H$, like $V P D$, Fwet and the different resistances contributed the most to the uncertainties of all the ET components. These results are in agreement with a study by Langensiepen, et al. [59], who reported that VPD is one of the principal meteorological variables in ET estimation using the PM model. Consequently, any error in 
the humidity and temperature measurement significantly impacts VPD uncertainty, and hence increases the overall uncertainty.

The overall mean relative ET uncertainty in our study was around $80 \%$ for both biomes, as measured from the propagation of input uncertainties. A similar approach was used to quantify the propagated ET uncertainty of several ET estimation methods, including the Penman method, in a riparian area of the Middle Rio Grande Basin, in New Mexico [5]. They used different values of input variable errors and obtained a much lower relative ET uncertainty, of only $10 \%$, on the Penman method. This notable difference is due to a number of issues, including the methods and ecoclimates under investigation, the difference in the determination of the individual input uncertainties and the number of input variables and parameters considered in the propagation. Our uncertainties were a product of the $\mathrm{U}_{\mathrm{A}}$ and $\mathrm{U}_{\mathrm{B}}$ estimates propagated from the core inputs, through intermediate parameters, through to the final uncertainty product. In another study, predefined input uncertainty values from the manufacturers were used, for example, an Rnet uncertainty of $15 \%$, while we reported a low Rnet uncertainty of 3 and $4 \%$ for our sites [5]. Ferguson, et al. [60] evaluated the uncertainty contributions of input variables to the final ET output. They show that the overall contributions of $\alpha$ and $\varepsilon s$ to ET uncertainties were minor, whereas $L A I$ contributed quite substantially.

\subsection{Sensitivity of PM-Mu ET Estimates to Input Variables}

It is always a challenge to compare results on sensitivity analysis with other studies because of the difference between models, input variables and datasets, and the procedures being used to estimate the sensitivity coefficients. Moreover, these are applied under different ecoclimatic conditions under investigation. In our study, we used the simple one-at-a-time local sensitivity analysis method to estimate the sensitivity coefficients. Based on the maximum value of each input, we perturbed each of the input variables within the $\pm 20 \%$ range. Our results show that PM-Mu is most sensitive to Tair and LST, thus making them the most influential input variables in ET estimation in southern Africa using the PM-Mu method. This result is explained by the fact that in dry environments the air has a high capacity to hold water vapour, which can then transfer energy to the land surface. Meanwhile, our results also show that the land surface parameters, like $\varepsilon a, L A I$ and $\alpha$, have little effect on the PM method in these semi-arid ecoclimates. These results are consistent with other studies in similar semi-arid/arid regions, where the PM model was reported to be most sensitive to Tair [61,62]. A comprehensive sensitivity analysis assessment of the PM and Priestley-Taylor models to various inputs in different climates in Australia, Guo, et al. [26] showed that these models were most sensitive to Tair.

Other studies in similar dry climates contradict, however, our finding that PM-Muestimated ET is most sensitive to air and land surface temperatures. Tabari and Hosseinzadeh Talaee [63] observed that $\mathrm{ET}_{\mathrm{o}}$ was more sensitive to wind speed in a semi-arid climate, with less sensitivity to Tair and sunshine hours. Garcia, et al. [64] also reported that wind speed is a critical variable in $\mathrm{ET}_{\mathrm{o}}$ estimation in arid and semi-arid climates. They reasoned that this is because of the importance of the aerodynamic term under dry and high wind speed conditions. Gong, et al. [65] reported that the reference ET was most sensitive to $R H$ variations, followed by solar radiation, in the Changjiang basin, in China.

\section{Conclusions}

In this study, we conducted a comprehensive uncertainty and sensitivity assessment of the PM-Mu model with regard to both meteorological and land surface characteristics in situ, i.e., air temperature and relative humidity, and remote sensing input variables, i.e., LAI, LST, $\varepsilon_{S}$ and $\alpha$, in both savanna and grassland biomes of southern Africa. We only investigated the input variable uncertainties and quantified how these were propagated to the final ET uncertainty, and not the uncertainties related to the model algorithms used. With average relative uncertainties of $10 \pm 3.5 \%$ and $6 \pm 1.9 \%$ for Skukuza and Welgegund, respectively, $\mathrm{RH}$, including its derivative, VPD, contributed the highest uncertainty to 
the final ET uncertainty. On the other hand, these results highlight that land surface and air temperatures and surface emissivity contributed the most to the solar net radiation uncertainty. Our results showed an overall ET uncertainty of approximately $80 \%$ in both biomes. This final propagated uncertainty is considerably larger than those reported in other studies. A number of reasons have been highlighted, including the number of input variables assessed for their uncertainty contribution, the assumption that there is no correlation between the input variables and the uncertainty analysis method used, that gives the total uncertainty as a combination of Type A and Type B uncertainties. This highlights the importance of accurate input data collection in ET estimation, as any errors are propagated to the final product. In contrast, the PM model was most sensitive to air and land surface temperatures, indicating the importance of these input variables to ET estimation using the PM-Mu model in our study areas. However, the sensitivity of the PM-Mu model to land surface parameters was quite low.

Author Contributions: Conceptualisation, N.P.M., C.M.M., A.R., R.M. and W.V.; methodology, N.P.M., C.M.M., A.R., N.P.M., C.M.M. and A.R.; formal analysis, N.P.M.; investigation, N.P.M.; resources, R.M., C.M.M.; data curation, N.P.M.; writing—original draft preparation, N.P.M.; writingreview and editing, C.M.M., A.R., R.M. and W.V.; visualisation, N.P.M.; supervision, C.M.M. and R.M.; project administration, N.P.M.; funding acquisition, N.P.M. and R.M. All authors have read and agreed to the published version of the manuscript.

Funding: Council for Scientific and Industrial Research under the project Natural Resources and Environment Parliamentary Grant and the Young Researcher Establishment Fund.

Conflicts of Interest: The authors declare no conflict of interest. The funders had no role in the design of the study; in the collection, analyses, or interpretation of data; in the writing of the manuscript, or in the decision to publish the results.

\section{References}

1. Allen, R.G.; Tasumi, M.; Morse, A.; Trezza, R.; Wright, J.L.; Bastiaanssen, W.; Kramber, W.; Lorite, I.; Robison, C.W. Satellite-based energy balance for mapping evapotranspiration with internalized calibration (METRIC)—Applications. J. Irrig. Drain. Eng. 2007, 133, 395-406. [CrossRef]

2. Bastiaanssen, W.G.M.; Noordman, E.J.M.; Pelgrum, H.; Davids, G.; Thoreson, B.P.; Allen, R.G. SEBAL model with remotely sensed data to improve water-resources management under actual field conditions. J. Irrig. Drain. Eng. 2005, 131, 85-93. [CrossRef]

3. Bowen, I.S. The ratio of heat losses by conduction and by evaporation from any water surface. Phys. Rev. 1926, 27, 779. [CrossRef]

4. Monteith, J.L. Evaporation and surface temperature. Q. J. R. Meteorol. Soc. 1981, 107, 1-27. [CrossRef]

5. Nichols, J.; Eichinger, W.; Cooper, D.; Prueger, J.; Hipps, L.; Neale, C.; Bawazir, A. Comparison of Evaporation Estimation Methods for a Riparian Area; College of Engineering, University of Iowa: Iowa City, IA, USA, 2004; p. 50.

6. Su, Z. The Surface Energy Balance System (SEBS) for estimation of turbulent heat fluxes. Hydrol. Earth Syst. Sci. Discuss. 2002, 6, 85-100. [CrossRef]

7. Vinukollu, R.K.; Wood, E.F.; Ferguson, C.R.; Fisher, J.B. Global estimates of evapotranspiration for climate studies using multi-sensor remote sensing data: Evaluation of three process-based approaches. Remote Sens. Environ. 2011, 115, 801-823. [CrossRef]

8. Ershadi, A.; McCabe, M.F.; Evans, J.P.; Chaney, N.W.; Wood, E.F. Multi-site evaluation of terrestrial evaporation models using FLUXNET data. Agric. For. Meteorol. 2014, 187, 46-61. [CrossRef]

9. McCabe, M.F.; Ershadi, A.; Jimenez, C.; Miralles, D.G.; Michel, D.; Wood, E.F. The GEWEX LandFlux project: Evaluation of model evaporation using tower-based and globally-gridded forcing data. Geosci. Model Dev. Discuss. 2015, 8, 6809-6866.

10. Michel, D.; Jiménez, C.; Miralles, D.G.; Jung, M.; Hirschi, M.; Ershadi, A.; Martens, B.; McCabe, M.; Fisher, J.B.; Mu, Q.; et al. The WACMOS-ET project - Part 1: Tower-scale evaluation of four remote-sensing-based evapotranspiration algorithms. Hydrol. Earth Syst. Sci. 2016, 20, 803-822. [CrossRef]

11. Saltelli, A.; Tarantola, S.; Campolongo, F.; Ratto, M. Sensitivity Analysis in Practice: A Guide to Assessing Scientific Models; Wiley: Chichester, UK, 2004.

12. Brugnach, M.; Pahl-Wostl, C.; Lindenschmidt, K.; Janssen, J.; Filatova, T.; Mouton, A.; Holtz, G.; Van der Keur, P.; Gaber, N. Chapter four complexity and uncertainty: Rethinking the modelling activity. Dev. Integr. Environ. Assess. 2008, 3, 49-68.

13. Bich, W.; Cox, M.G.; Dybkaer, R.; Elster, C.; Estler, W.T.; Hibbert, B.; Imai, H.; Kool, W.; Michotte, C.; Nielsen, L. Revision of the 'Guide to the Expression of Uncertainty in Measurement'. Metrologia 2012, 49, 702. [CrossRef]

14. Saltelli, A.; Annoni, P. How to avoid a perfunctory sensitivity analysis. Environ. Model. Softw. 2010, 25, 1508-1517. [CrossRef]

15. Morio, J. Global and local sensitivity analysis methods for a physical system. Eur. J. Phys. 2011, 32, 1577. [CrossRef] 
16. Yang, S.; Tian, W.; Cubi, E.; Meng, Q.; Liu, Y.; Wei, L. Comparison of sensitivity analysis methods in building energy assessment. Procedia Eng. 2016, 146, 174-181. [CrossRef]

17. Nguyen, A.-T.; Reiter, S. A performance comparison of sensitivity analysis methods for building energy models. Build. Simul. 2015, 8, 651-664. [CrossRef]

18. Frey, C.H.; Patil, S.R. Identification and review of sensitivity analysis methods. Risk Anal. 2002, 22, 553-578. [CrossRef]

19. Hamby, D.M. A review of techniques for parameter sensitivity analysis of environmental models. Environ. Monit. Assess. 1994, 32, 135-154. [CrossRef]

20. Hamby, D.M. A comparison of sensitivity analysis techniques. Health Phys. 1995, 68, 195-204. [CrossRef]

21. Lilburne, L.; Tarantola, S. Sensitivity analysis of spatial models. Int. J. Geogr. Inf. Sci. 2009, 23, 151-168. [CrossRef]

22. Saint-Geours, N.; Lilburne, L. Comparison of three spatial sensitivity analysis techniques. In Proceedings of the 9th International Symposium on Spatial Accuracy Assessment in Natural Resources and Environmental Sciences, Leicester, UK, 20-23 July 2010; pp. 421-424.

23. Talsma, C.J.; Good, S.P.; Miralles, D.G.; Fisher, J.B.; Martens, B.; Jimenez, C.; Purdy, A.J. Sensitivity of evapotranspiration components in remote sensing-based models. Remote Sens. 2018, 10, 1601. [CrossRef]

24. Pérez, M.; Ángel, J.; García-Galiano, S.G.; Martin-Gorriz, B.; Baille, A. Satellite-based method for estimating the spatial distribution of crop evapotranspiration: Sensitivity to the priestley-taylor coefficient. Remote Sens. 2017, 9, 611. [CrossRef]

25. Sharifi, A.; Dinpashoh, Y. Sensitivity Analysis of the Penman-Monteith reference Crop Evapotranspiration to Climatic Variables in Iran. Water Resour. Manag. 2014, 28, 5465-5476. [CrossRef]

26. Guo, D.; Westra, S.; Maier, H.R. Sensitivity of potential evapotranspiration to changes in climate variables for different Australian climatic zones. Hydrol. Earth Syst. Sci. 2017, 21, 2107-2126. [CrossRef]

27. Westerhoff, R. Using uncertainty of Penman and Penman-Monteith methods in combined satellite and ground-based evapotranspiration estimates. Remote Sens. Environ. 2015, 169, 102-112. [CrossRef]

28. Hofreiter, M.; Jirka, V. Uncertainty Analysis of Evapotranspiration Estimates in Ecosystems. Asian Rev. Mechnical Eng. 2012, 1, 46.

29. Chen, L.-H.; Chen, J.; Chen, C. Effect of Environmental Measurement Uncertainty on Prediction of Evapotranspiration. Atmosphere 2018, 9, 400. [CrossRef]

30. RefGrab-It Install Page. Vol. 2014. Available online: https://www.refworks.com/refgrabit/linkpage.aspx (accessed on 1 January 2021).

31. Van der Kwast, J.; Timmermans, W.; Gieske, A.; Su, Z.; Olioso, A.; Jia, L.; Elbers, J.; Karssenberg, D.; De Jong, S.; de Jong, S. Evaluation of the Surface Energy Balance System (SEBS) applied to ASTER imagery with flux-measurements at the SPARC 2004 site (Barrax, Spain). Hydrol. Earth Syst. Sci. Discuss. 2009, 6, 1165-1196.

32. Wang, J.; Sammis, T.; Gutschick, V.; Gebremichael, M.; Miller, D. Sensitivity analysis of the surface energy balance algorithm for land (SEBAL). Trans. ASABE 2009, 52, 801-811. [CrossRef]

33. Majozi, N.P.; Mannaerts, C.M.; Ramoelo, A.; Mathieu, R.; Mudau, A.E.; Verhoef, W. An intercomparison of satellite-based daily evapotranspiration estimates under different eco-climatic regions in South Africa. Remote Sens. 2017, 9, 307. [CrossRef]

34. Mu, Q.; Heinsch, F.A.; Zhao, M.; Running, S.W. Development of a global evapotranspiration algorithm based on MODIS and global meteorology data. Remote Sens. Environ. 2007, 111, 519-536. [CrossRef]

35. Mu, Q.; Zhao, M.; Running, S.W. Improvements to a MODIS global terrestrial evapotranspiration algorithm. Remote Sens. Environ. 2011, 115, 1781-1800. [CrossRef]

36. Scholes, R.J.; Bond, W.J.; Eckhardt, H.C. Vegetation Dynamics in the Kruger Ecosystem; The Kruger Experience: Ecology and Management of Savanna Heterogeneity; Island Press: Washington, DC, USA, 2003.

37. Scholes, R.J.; Gureja, N.; Giannecchinni, M.; Dovie, D.; Wilson, B.; Davidson, N.; Piggott, K.; McLoughlin, C.; Van der Velde, K.; Freeman, A. The environment and vegetation of the flux measurement site near Skukuza, Kruger National Park. Koedoe-Afr. Prot. Area Conserv. Sci. 2001, 44, 73-83. [CrossRef]

38. Räsänen, M.; Aurela, M.; Vakkari, V.; Beukes, J.P.; Tuovinen, J.-P.; Van Zyl, P.G.; Josipovic, M.; Venter, A.D.; Jaars, K.; Siebert, S.J. Carbon balance of a grazed savanna grassland ecosystem in South Africa. Biogeosciences 2017, 14, 1039. [CrossRef]

39. Wan, Z. MODIS land-surface temperature algorithm theoretical basis document (LST ATBD). Inst. Comput. Earth Syst. Sci. St. Barbar. 1999, 75.

40. Hulley, G.; Malakar, N.; Hughes, T.; Islam, T.; Hook, S. Moderate Resolution Imaging Spectroradiometer (MODIS) MOD21 Land Surface Temperature and Emissivity Algorithm Theoretical Basis Document; Jet Propulsion Laboratory, National Aeronautics and Space: Pasadena, CA, USA, 2016; p. 102.

41. Wanner, W.; Strahler, A.; Hu, B.; Lewis, P.; Muller, J.P.; Li, X.; Schaaf, C.B.; Barnsley, M. Global retrieval of bidirectional reflectance and albedo over land from EOS MODIS and MISR data: Theory and algorithm. J. Geophys. Res. Atmos. 1997, 102, 17143-17161. [CrossRef]

42. Schaaf, C.; Liu, J.; Gao, F.; Strahler, A.H. MODIS albedo and reflectance anisotropy products from Aqua and Terra. Land Remote Sens. Glob. Environ. Chang. NASA's Earth Obs. Syst. Sci. ASTER MODIS 2011, 11, 549-561.

43. Schaaf, C.B.; Gao, F.; Strahler, A.H.; Lucht, W.; Li, X.; Tsang, T.; Strugnell, N.C.; Zhang, X.; Jin, Y.; Muller, J.-P. First operational BRDF, albedo nadir reflectance products from MODIS. Remote Sens. Environ. 2002, 83, 135-148. [CrossRef]

44. Nobre, C.A.; Sellers, P.J.; Shukla, J. Amazonian deforestation and regional climate change. J. Clim. 1991, 4, 957-988. [CrossRef] 
45. Sellers, P.; Meeson, B.; Hall, F.; Asrar, G.; Murphy, R.; Schiffer, R.; Bretherton, F.; Dickinson, R.; Ellingson, R.; Field, C. Remote sensing of the land surface for studies of global change: Models-algorithms—experiments. Remote Sens. Environ. 1995, 51, 3-26. [CrossRef]

46. Jin, Y.; Schaaf, C.B.; Woodcock, C.E.; Gao, F.; Li, X.; Strahler, A.H.; Lucht, W.; Liang, S. Consistency of MODIS surface bidirectional reflectance distribution function and albedo retrievals: 2. Validation. J. Geophys. Res. Atmos. 2003, 108. [CrossRef]

47. Wang, K.; Liu, J.; Zhou, X.; Sparrow, M.; Ma, M.; Sun, Z.; Jiang, W. Validation of the MODIS global land surface albedo product using ground measurements in a semidesert region on the Tibetan Plateau. J. Geophys. Res. Atmos. 2004, 109. [CrossRef]

48. Knyazikhin, Y.; Glassy, J.; Privette, J.; Tian, Y.; Lotsch, A.; Zhang, Y.; Wang, Y.; Morisette, J.; Votava, P.; Myneni, R. MODIS Leaf Area Index (LAI) and Fraction of Photosynthetically Active Radiation Absorbed by Vegetation (FPAR) Product (MOD15) Algorithm Theoretical Basis Document; Theoretical Basis Document, NASA Goddard Space Flight Center: Greenbelt, MD, USA, 1999 ; Volume 20771.

49. Myneni, R.B.; Ramakrishna, R.; Nemani, R.; Running, S.W. Estimation of global leaf area index and absorbed PAR using radiative transfer models. IEEE Trans. Geosci. Remote Sens. 1997, 35, 1380-1393. [CrossRef]

50. Fang, H.; Wei, S.; Jiang, C.; Scipal, K. Theoretical uncertainty analysis of global MODIS, CYCLOPES, and GLOBCARBON LAI products using a triple collocation method. Remote Sens. Environ. 2012, 124, 610-621. [CrossRef]

51. Strahler, A.H.; Muller, J.; Lucht, W.; Schaaf, C.; Tsang, T.; Gao, F.; Li, X.; Lewis, P.; Barnsley, M.J. MODIS BRDF/albedo product: Algorithm theoretical basis document version 5.0. MODIS Doc. 1999, 23, 42-47.

52. Muniz, P.R.; Kalid, R.D.A.; Cani, S.P.; Magalhães, R.S. Handy method to estimate uncertainty of temperature measurement by infrared thermography. Opt. Eng. 2014, 53, 074101. [CrossRef]

53. Lin, X.; Hubbard, K. Uncertainties of derived dewpoint temperature and relative humidity. J. Appl. Meteorol. 2004, 43, 821-825. [CrossRef]

54. Hulley, G.C.; Hughes, C.G.; Hook, S.J. Quantifying uncertainties in land surface temperature and emissivity retrievals from ASTER and MODIS thermal infrared data. J. Geophys. Res. Atmos. 2012, 117. [CrossRef]

55. Mira, M.; Olioso, A.; Gallego-Elvira, B.; Courault, D.; Garrigues, S.; Marloie, O.; Hagolle, O.; Guillevic, P.; Boulet, G. Uncertainty assessment of surface net radiation derived from Landsat images. Remote Sens. Environ. 2016, 175, 251-270. [CrossRef]

56. Ershadi, A.; McCabe, M.; Evans, J.; Wood, E. Impact of model structure and parameterization on Penman-Monteith type evaporation models. J. Hydrol. 2015, 525, 521-535. [CrossRef]

57. Bailey, W.; Davies, J. Evaporation from soybeans. Bound.-Layer Meteorol. 1981, 20, 417-428. [CrossRef]

58. Irmak, S.; Mutiibwa, D. On the dynamics of stomatal resistance: Relationships between stomatal behavior and micrometeorological variables and performance of Jarvis-type parameterization. Trans. ASABE 2009, 52, 1923-1939. [CrossRef]

59. Langensiepen, M.; Fuchs, M.; Bergamaschi, H.; Moreshet, S.; Cohen, Y.; Wolff, P.; Jutzi, S.C.; Cohen, S.; Rosa, L.M.G.; Li, Y.; et al. Quantifying the uncertainties of transpiration calculations with the Penman-Monteith equation under different climate and optimum water supply conditions. Agric. For. Meteorol. 2009, 149, 1063-1072. [CrossRef]

60. Ferguson, C.R.; Sheffield, J.; Wood, E.F.; Gao, H. Quantifying uncertainty in a remote sensing-based estimate of evapotranspiration over continental USA. Int. J. Remote Sens. 2010, 31, 3821-3865. [CrossRef]

61. Eslamian, S.; Khordadi, M.J.; Abedi-Koupai, J. Effects of variations in climatic parameters on evapotranspiration in the arid and semi-arid regions. Glob. Planet. Chang. 2011, 78, 188-194. [CrossRef]

62. Debnath, S.; Adamala, S.; Raghuwanshi, N.S. Sensitivity Analysis of FAO-56 Penman-Monteith Method for Different Agroecological Regions of India. Environ. Process. 2015, 2, 689-704. [CrossRef]

63. Tabari, H.; Hosseinzadeh Talaee, P. Sensitivity of evapotranspiration to climatic change in different climates. Glob. Planet. Chang. 2014, 115, 16-23. [CrossRef]

64. Garcia, M.; Raes, D.; Allen, R.; Herbas, C. Dynamics of reference evapotranspiration in the Bolivian highlands (Altiplano). Agric. For. Meteorol. 2004, 125, 67-82. [CrossRef]

65. Gong, L.; Xu, C.-Y.; Chen, D.; Halldin, S.; Chen, Y.D. Sensitivity of the Penman-Monteith reference evapotranspiration to key climatic variables in the Changjiang (Yangtze River) basin. J. Hydrol. 2006, 329, 620-629. [CrossRef] 